\title{
A RECEPÇÃO DO GÊNERO CONTO EM “NO CASTELO QUE SE VAI”, DE MARINA COLASANTI
}

\author{
Silmara Ribeiro Moscatelli \\ Universidade Estadual Paulista - UNESP, Faculdade de Ciências e Letras, Assis, SP. E-mail: \\ silmaracarvalhoribeiro@gmail.com
}

\begin{abstract}
RESUMO
A presente pesquisa objetiva investigar a subversão do gênero do conto de fadas tradicional na obra No castelo que se vai, de Marina Colasanti, do livro Entre a espada e a Rosa (1992), a fim de explicitar o modo como a autora narra sua história para, através da linguagem, construir seu tema. Além da análise do conto, procedeu-se também a análise de um material de apoio à leitura, elaborado e oferecido pela Secretaria da Educação do Estado de São Paulo, em 2012, com o intuito de subsidiar o trabalho dos professores de língua portuguesa, para que estes promovam uma leitura prazerosa e competente. Pretende-se, nessa segunda análise, verificar se o material de apoio em questão contempla, por meio das estratégias de leitura propostas, um estudo da construção linguística do conto e da preparação de um simples leitor para o leitor-modelo, responsável e crítico, capaz de construir o sentido de modo autônomo e de argumentar sua recepção.

Palavras-chave: Leitura; Conto Literário; Ensino Público; Competência Leitora; Estética da Recepção.
\end{abstract}

The reception tale genre in "No castelo que se vai" (At the castle that goes away), by Marina Colasanti.

\begin{abstract}
The present research aims at investigating the subversion of the traditional fairy tale in the work No castelo que se vai (At the castle that goes away), by Marina Colasanti, in the book Entre a espada e a Rosa (Between the sword and the Rose) (1992), in order to explain how the author narrates the story so that, through language, it can built its theme. Besides the analysis of the short story, we performed an analysis of a supporting material for reading, elaborated and offered in 2001 by the Secretary of Education of the State of São Paulo, with the objective of basing the work of Portuguese teachers so that they can promote competent and pleasant reading for their students. We intend to, in this second analysis, to find out if the mentioned supporting material contemplates, through the proposed reading strategies, a study of linguistic construction of the short story and the preparation of a simple reader into a model-reader, responsible and critical, able to build the meaning in an autonomous way and argue its reception.
\end{abstract}

Keywords: Reading; Literary Short Story; Public Teaching; Reading Competency, Aesthetics of Reception. 


\section{INTRODUÇÃO}

Um dos grandes desafios dos professores de escola regular no Ensino Fundamental II está relacionado à leitura, e esse 'drama' aumenta quando se trata de um texto literário. Muitos alunos acreditam que a leitura desse tipo de texto é difícil, sem funcionalidade e que sempre haverá uma prova, com o único objetivo de atribuir uma nota. Sabe-se que o texto literário desenvolve a imaginação, a criticidade, o domínio da linguagem e auxilia o leitor a desenvolver um pensamento crítico e reflexivo diante de sua própria vida e perante a sociedade. Segundo Culler (1999, p. 110),

A literatura não apenas faz da identidade um tema; ela desempenha um papel significativo na construção da identidade dos leitores. O valor da literatura há muito tempo foi vinculado às experiências vicárias dos leitores possibilitando-lhes como é estar em situações específicas e desse modo conseguir a disposição para agir e sentir de certas maneiras. As obras literárias encorajam a identificação com as personagens, mostrando as coisas do seu ponto de vista. As obras literárias, além de encorajar a identificação do leitor com as personagens, também auxiliam no desenvolvimento de sua própria opinião. Por isso, o interesse em investigar a leitura de textos literários no Ensino Fundamental II, uma vez que muitos são os cursos de formação oferecidos aos professores da rede estadual de ensino, com o objetivo de despertar nos alunos uma leitura prazerosa e significativa, porém, os resultados ainda deixam a desejar. Apesar da informação e do conhecimento serem difundidos de maneira rápida, o que se observa são leitores e escritores que ficam apenas na superfície do texto, quando o que se espera, na verdade, são leitores que criem um ambiente cultural no qual os livros e a literatura adquiram um significado privilegiado, de modo a propiciar o desenvolvimento intelectual, cultural, econômico e social de cada indivíduo. Diante dessa situação, as questões relacionadas à formação de leitores literários competentes têm sido o centro da atenção para os professores, pesquisadores e coordenadores de núcleos pedagógicos, que buscam alternativas e caminhos para que os leitores leiam de maneira significativa e, ao mesmo tempo, com prazer.

Dessa forma, as estratégias de leitura desenvolvidas nos materiais de apoio buscam conscientizar o leitor sobre a importância do ato de ler. Entretanto, é possível constatar que há uma grande dificuldade, por parte dos alunos, em estabelecer um elo de significados na leitura, entre a linguagem utilizada, o meio social e a expressão cultural. Nesta perspectiva, o presente trabalho se apresenta com o intuito de investigar uma situação real do espaço de atuação profissional da professora responsável pelas aulas de Língua Portuguesa e também pesquisadora deste artigo, de modo a contribuir para a prática docente, na medida em que poderá conhecer os hábitos de leitura dos discentes, a maneira como analisam as narrativas e a interação apresentada pelo grupo diante do texto literário.

Com o objetivo de contribuir para a prática educativa que envolve a leitura literária, esta pesquisa propõe um estudo sobre a recepção do conto "No castelo que se vai", de Marina Colasanti, que se encontra no livro Entre a espada e a rosa, publicado em 1992. A pesquisa foi feita com uma turma do 60 ano do Ensino Fundamental II, da rede pública de ensino do estado de São Paulo. Com isso, pretendeu-se averiguar se é possível trabalhar em sala de aula com obras de boa qualidade literária, para possibilitar aos alunos a compreensão dos aspectos formais, estilísticos e temáticos da mesma.

\section{METODOLOGIA DA PESQUISA}

Esta pesquisa tem caráter predominantemente qualitativo, pois segue um delineamento metodológico descritivo para discutir como a prática pedagógica fundamentada na Estética da Recepção pode auxiliar no ensino de literatura e na maneira como o leitor analisa o texto. Para alcançar os objetivos, os passos metodológicos foram organizados da seguinte maneira: selecionar a turma, considerar os sujeitos envolvidos, o contexto em que a investigação será realizada e os instrumentos utilizados na coleta de dados. O procedimento metodológico eleito para a 
realização desta pesquisa foi a investigação qualitativa, já que permite ao pesquisador ter contato direto e prolongado com a situação que está sendo pesquisada, possibilitando-lhe vivenciar a realidade, ou seja, ter "o ambiente natural como sua fonte direta de dados" (LÜDKE; ANDRÉ, 1986, p. 11); assim, afirmam que a pesquisa qualitativa: "[...] envolve a obtenção de dados descritivos, obtidos no contato direto do pesquisador com a situação estudada, enfatiza mais o processo do que o produto e se preocupa em retratar a perspectiva dos participantes".

Seguindo essa metodologia, a pesquisa se dividirá em quatro momentos distintos:

1. Pesquisa bibliográfica;

2. Análise do conto "No castelo que se vai", de Marina Colasanti;

3. Leitura do conto, junto com as estratégias de leitura proposta pelo material Sabores da Leitura, para alunos do 60 ano do Ensino Fundamental II.

4. Aplicação de questionários, baseados no método recepcional, com o objetivo de verificar a recepção do conto "No castelo que se vai" pelos alunos e os aspectos envolvidos nesse processo (escola, comunidade, experiências culturais).

Segundo Erickson (1988), ao abordar sobre a investigação qualitativa, declara que esse tipo de pesquisa tem o caráter interpretativo, já que: "centra-se em aspectos específicos do significado e da ação da vida social que se desenvolve em cenas concretas de interação face a face na sociedade que rodeia a cena em ação" (p. 289-290). Assim, Erickson (1986, p. 119) afirma:

[...] esta modalidade de pesquisa desenvolve-se a partir da delimitação do contexto de pesquisa, registro cuidadoso - anotações ou recopilações - do que está sendo estudado, reflexão sobre os registros e elaboração de informes descritivos, um que contemple fragmentos narrativos e citações textuais provenientes dos registros coletados e outro que seja mais geral, em forma de diagrama, quadro sinóptico e/ou estatística descritiva.

Por isso, alguns aspectos quantitativos também foram explorados neste trabalho, como, por exemplo, nas descrições e exposições de números estatísticos que ajudam a esclarecer determinadas respostas no momento da análise do conto.

\section{DISCUSSÃO}

Neste trabalho, apresentou-se um estudo da recepção do conto: No castelo que se vai, que aborda valores morais e éticos, por meio da subversão do gênero conto de fadas, pois o herói da narrativa ganha a luta sem brigar. Essas subversões exploradas por Colasanti levam ao leitor a ampliar seu campo imaginário e, guiados pelo narrador, a participar da estruturação da obra, a preencher os vazios deixados pelo texto. Ao considerar o texto como um espaço de comunicação com a vida, concorda-se com a ideia de que o diálogo entre leitor e obra literária não termina na última linha lida, mas reverbera por muito tempo. Por isso, esta pesquisa foi fundamentada para salientar a importância do expectador, ou seja, o leitor.

A literatura permite ao leitor participar da construção do texto, mas, para que isso ocorra, é necessário que a concretização da leitura parta da interação entre leitor - texto - autor. Aliados as estratégias de leitura propostas por Bignotto (ano), tenta-se comprovar a conciliação entre a prática de ensino de literatura sem perder o foco no estudo literário. Assim, dentre as várias metodologias, escolheu-se a Estética da Recepção, pelo fato de privilegiar o papel do leitor diante da obra literária, fato este que o material também propõe nas suas etapas. Ao chegar aos resultados, constata-se que o desafio em formar leitores-modelos é grande.

Apesar de trabalhar com um grupo cujas características sociais, econômicas e culturais são parecidas, eles se isolam, porque carregam em si o seu próprio repertório, as suas experiências de vida, ou de acordo com a Estética da Recepção, o seu próprio horizonte de expectativas. Esses aspectos puderam ser revelados no decorrer da pesquisa, pois ficaram expostos nos instrumentos 
utilizados - gravação da aula, nos questionários e nos debates a individualidade dos sujeitos envolvida em toda a homogeneidade do grupo.

Sendo assim, a partir das respostas e dos comentários oferecidos pelos alunos/leitores, abordou-se uma situação concreta para destacar algumas características gerais do processo de leitura. Em um cenário escolar, leitores do 6ㅇa ano do Ensino Fundamental II de escola pública do Oeste Paulista leram o conto, a partir da motivação exterior, pela solicitação da professorapesquisadora desta dissertação. Mas, apesar disso, a leitura gerou efeitos de satisfação, pois o conto atendeu às expectativas dos alunos. Nesse momento, percebe-se que o material de apoio foi de grande valia, pois as estratégias propostas geraram experiências consistentes dentro da sala de aula para o incentivo da leitura do texto literário.

Com essa abordagem metodológica, os aspectos estéticos do texto são ressaltados, por isso, quando o olhar da pesquisa se deteve para a Ruptura do Horizonte de Expectativas e o Questionamento do horizonte de Expectativas, método recepcional proposto por Bordini e Aguiar (1988), constatou-se que $95 \%$ dos alunos conseguiram, ao final de todo o processo, entender que o texto literário possui pistas, que orientam o leitor a consolidar sua leitura. Essa foi uma das principais metas da pesquisa, fazer com que os alunos expressassem suas impressões pessoais sobre a obra, mas, percebessem que há uma construção dentro do texto literário, em que se encontra limites para a interpretação. Os alunos ao romper as expectativas anteriores à leitura do conto, fez com que nesta etapa da pesquisa muitos escrevessem de um modo parecido e vissem a leitura pelo mesmo ângulo, foram poucos os alunos que não conseguiram, por exemplo, identificar os elementos da narrativa do conto em estudo de maneira correta.

\section{CONCLUSÃO}

Ao eleger a Estética da Recepção como fundamento teórico desta pesquisa, sabe-se que o leitor esperado tanto por Jauss (1994) quanto por Iser (1996), é um leitor especial, com um horizonte de expectativas já formado, com habilidades e referências específicas. Seria o leitormodelo, como propõe Umberto Eco, que a leitura do texto literário para consolidar nesse processo dialógico, necessita de um autor - empírico (o que idealiza a obra) pressupõe um leitor modelo (a quem se destina a obra); no momento de comunicação o leitor - empírico (o que efetivamente lê a obra) deve seguir as orientações do leitor - modelo (presente na obra dando instruções ao leitor para concretizar a leitura) para atingir a fruição. Esse leitor, idealizado por todos esses teóricos, deve entender profundamente de fatores estéticos e literários. Apesar de os alunos do 60 ano do Ensino Fundamental II não conhecerem essa teoria literária, conseguiram, com o auxílio do mediador, construir significados pertinentes. No caso dos alunos envolvidos na pesquisa, constatou-se que metade do grupo teve dificuldade em perceber que o conto da Marina Colasanti dialoga com o conto de fadas tradicional. Outra questão que alguns alunos tiveram dificuldade de atualizar a obra foi: Imagine se o Rei do Nada contasse a história ou Rei Raiç, seria contada do mesmo jeito? $75 \%$ disseram que não seria contada do mesmo jeito e $25 \%$ não conseguiram perceber que quando muda o narrador, todo o contexto e toda a história é modificada.

Mas, quando se fez a análise de todas as perguntas dessa etapa, comprova-se que é possível, por meio de estratégias bem definidas, aulas dialogadas e a mediação do professor, o aluno caminhar para ser um leitor modelo. Não se pode afirmar, ao final dessa pesquisa, que os alunos que participaram dessas aulas, com essa metodologia, são leitores modelo. Isso de fato ainda não aconteceu, mas comprova-se, por meio dos dados, que este conto, aliado às estratégias de leitura e ao método recepcional, fez com que a maioria dos alunos conseguissem realizar uma leitura amadurecida da obra. Além disso, essa distância entre os leitores reais e os leitores modelos não diminui a leitura de um grupo. Por meio do método recepcional de Bordini e Aguiar (1988) e os níveis de leitura de Kügler (1987) percebe-se que o grupo é capaz de abstrair 
conhecimentos importantes sobre o texto literário, de acordo com o seu horizonte de expectativas e das estratégias utilizadas pelo mediador da leitura para provocá-los a preencher os 'vazios' do texto.

Assim, a prática de leitura deve ser pensada na formação do leitor ativo, que constrói sentidos junto com o texto, analisando-o dialogicamente. Segundo Zilberman (1986, p.103): “é pelo exercício do ato de ler que se singulariza o leitor, e este torna tanto mais saliente, quanto mais pessoal for seu posicionamento no desempenho daquela atividade". Dessa maneira, pensar em estratégias para trabalhar com o texto literário é o primeiro passo para contornar alguns problemas para a formação de leitores, tais como: escolha de obras que possam afastar definitivamente o leitor de seu processo de formação. É preciso começar atendendo de alguma maneira ao horizonte de expectativas dos estudantes, para depois, rompê-lo. Além de estabelecer estratégias de leitura, o professor precisa assumir o papel de mediador para traçar os objetivos que deseja alcançar; assim, conseguirá compreender como os alunos recebem a obra literária e isso facilita todo o processo de ensino e aprendizagem.

Portanto, a leitura de textos literários acompanhadas de estratégias de leitura bem definidas combinadas a Estética da Recepção permite a formação de leitores autônomos que, diante de uma obra que lhes cause estranhamento, possam recorrer às suas experiências literárias e interpretar o novo, sempre observando as instruções presentes no texto literário, suas convenções e normas, para recriar sentimentos e valores culturais e sociais. Com isso, a literatura torna-se também capaz de recriar indivíduos, promover a atualização da obra e permitir a fruição estética.

\section{REFERÊNCIAS}

BIGNOTTO, C. Sabores da leitura. São Paulo: Secretaria da Educação, 2012.

BOGDAN, R.; BIKLEN, S. Investigação qualitativa em educação: uma introdução à teoria e aos métodos. Porto: Porto Ed., 1994. (Ciências da Educação, 12).

BRANDÃO, H. N.; MICHELETTI, G. Teoria e prática de leitura. In: Aprender e ensinar com textos didáticos e paradidáticos. São Paulo: Cortez, 1997.

COLASANTI, M. Entre a espada e a rosa. 3 ed. São Paulo, Salamandra, 1992.

COLOMER, T; CAMPS, A. Andar entre livros: a leitura literária na escola. Trad. Laura Sandroni. São Paulo: Global, 2007.

. Ensinar a ler, ensinar a compreender. Trad. F. Murad. Porto Alegre: Artmed, 2003.

CULLER, Jonathan. Teoria Literária: uma introdução. São Paulo: Beca Produções Culturais, 1999.

DIONÍSIO, A. P. Gêneros multimodais e multiletramento. In:KARWOSKI, A. M. GAYDECZKA, B. BRITO, K.S.(org.) Gêneros textuais: Reflexões e Ensino. Palmas e União da Vitória: Kaygangue, 2005.

ECO, U. Narratologia: lector in fabula. Trad. Attílio Cancian. São Paulo: Perspectiva, 2004. (Coleção Estudos)

. Os limites da interpretação. 2a ed. São Paulo: Perspectiva, 1990

Interpretação e Superinterpretação. São Paulo: Martins Fontes, 1986 
. Lector in Fábula: a cooperação interpretativa nos textos narrativos. Tradução de Atílio Cancian. São Paulo: Perspectiva, 1986.

Obra Aberta: forma e indeterminação nas poéticas contemporâneas. São Paulo: Perspectiva, 1962.

ERICKSON, F. Métodos cualitativos de investigación sobre la enseñanza. In: WITTROCK, M.C. La investigación de la enseñanza, II: métodos qualitativos y de observación. Barcelona: Paidos, 1988, p. 192-301.

FIORIN, J. L. Introdução ao pensamento de Bakhtin. São Paulo: Ática, 2006.

HAUSER, A. Sociologia del arte. Barcelona: Labor, 1977. v. 4.

ISER, W. O ato da leitura - uma teoria do efeito estético. Vol. 1. Trad. J. Kretshmer. São Paulo: Editora 34, 1996.

JAUSS, H. R. A história da literatura como provocação literária. São Paulo: Ática, 1994.

JOUVE, V. A leitura. São Paulo: Unesp, 2002.

A história da literatura como provocação à teoria literária. Trad. de S. Tellaroli. São Paulo: Ática, 1994.

KLEIMAN, A. B. (Org.). Os significados do letramento. Campinas: Mercado das Letras. 2011.

LAJOLO, M. Literatura: leitores e leitura. São Paulo: Moderna, 2001.

LAVILLE, C.; DIONNE, J. A construção do saber: manual de metodologia da pesquisa em ciências humanas. Porto Alegre: ARTMED, 1999.

LUDKE, M; ANDRÉ, M.E.D.A. Pesquisa em educação. Abordagens qualitativas. São Paulo: EPU, 1986.

MAINGUENEAU, D. Análise do Discurso Literário. Trad. A. Sobral. São Paulo: Contexto, 2006

MARTINS, M. H. O que é leitura. São Paulo: Brasiliense, 2006. 